\title{
La oralidad y el legado de una justicia ancestral
}

\section{The orality and the legacy of an ancestral justice}

\author{
Luis Andrés Cucarella Galiana* \\ Álvaro Camargo Solano** \\ Claudia Martínez LONDOÑO ${ }^{* * *}$ \\ *Doctor en Derecho por las Universidades de Bolonia (Italia) y Valencia (España). Área de Derecho Procesal. \\ Departamento de Derecho Administrativo y Procesal. Correo electrónico: Luis.a.cucarella@uv.es. \\ **Doctor en Educación de la UPEL, Magister en Investigación, especializado en Derecho Administrativo. \\ ***Doctoranda en Derecho Universidad Nacional del Mar del Plata-Argentina- Magister en Derecho Administrativo
}

Fecha de recepción: 12 septiembre de 2019

Fecha de aprobación: 6 de diciembre de 2019

Para citar este artículo / To reference this article Cucarella,L. Camargo, A, Martínez, C (2019) La oralidad y el legado de una justicia ancestral. Inciso, 21(2) ; $229-243$

\begin{abstract}
Resumen
DOI: http://dx.doi.org/10.18634/incj.21v.2i.991

El presente artículo de carácter socio- jurídico, trata la importancia de la oralidad como medio comunicacional ancestral y su coincidencia posterior con el desarrollo de la lengua escrita. El objetivo central del documento es el rememorar la vigencia de la oralidad en los procesos para la impartición de justicia en el entorno contemporáneo. Se acude a soportar la revisión del tema en casos como la vigencia de la Ley de Origen en algunos grupos indígenas de Colombia y la permanencia del Tribunal de las Aguas en Valencia, España, como ejemplos de impartición de justicia oral en la actualidad. La importancia del tema radica en el relieve de la validez de la oralidad frente a la prevalencia de la escritura como archivo mnemónico. A partir del objetivo planteado, la delimitación metodológica corresponde a una investigación cualitativa de carácter descriptivo con un enfoque socio-jurídico, el escrito se circunscribe a diversas fuentes de raíz antropológica, histórica y lingüística, para recuerdo de la importancia de la oralidad en paralelo con la aparición y permanencia del lenguaje impreso. Todo ello valida la vigencia de los mecanismos orales de justicia ya avanzado en el tercer milenio.
\end{abstract}

Palabras clave: Cultura, justicia, memoria, tradición oral, sistemas jurídicos. 


\section{ABSTRACT}

This article of socio-legal, deals with the importance of orality as an ancestral communicational medium and its subsequent coincidence with the development of the written language. The central objective of the document is to recall the validity of orality in the processes for imparting justice in the contemporary environment. We are going to support the revision of the issue in cases such as the validity of the Law of Origin in some indigenous groups and the permanence of the Court of Waters in Valencia, Spain, as examples of oral justice delivery at present. The importance of the topic lies in the importance of the validity of orality versus the prevalence of writing as a mnemonic archive. The methodological delimitation of the writing is circumscribed to diverse sources of anthropological, historical and linguistic roots to remember the importance of orality in parallel with the appearance and permanence of printed language. All this validates the validity of the oral mechanisms in the delivery of justice already advanced the third millennium.

Key words: culture, justice, memory, tradition, oral tradition, language, cultural rights, legal systems, social systems.

\section{Introducción}

El presente artículo hace un sondeo no exhaustivo acerca del lenguaje oral, su importancia comunicacional y su transfiguración en lengua escrita, enfatizando en su permanencia como legado insustituible en el desarrollo social. Se parte de la formulación de la pregunta ¿Cuál es la vigencia de la oralidad en los procesos para impartición de justicia en el entorno contemporáneo?

Es así como, partiendo de las categorías de oralidad y legado ancestral se busca iniciar una reseña de lo que el lenguaje hablado ha significado para las generaciones actuales como mantenimiento de tradiciones que llevan en sí saberes, ritos y técnicas que son un legado universal para las civilizaciones actuales. Para dar respuesta a la pregunta de investigación el objetivo rector planteado está encaminado a determinar la vigencia de la oralidad en los procesos para impartición de justicia en el entorno contemporáneo, a través de una metodología cualitativa con un enfoque descriptivo de carácter socio-jurídico.

De manera muy concreta, la oralidad se refiere a un modo de comunicación que accede a la enunciación verbal a través de palabras y cuyo sistema se compone de unidades abstractas, los fonemas, así como del sonido o el vibrar de las cuerdas vocales de nuestro aparato. Pero más allá de la oralidad como descripción del acto fonador que distingue al ser humano como especie con mayor capacidad de comunicación simbólica mediante signos, se puede hablar de la oralidad como resultado de una primera etapa de la evolución humana. La transmisión resulta en una vía de información, exteriorización de ideas, traducción de mitos, leyendas, anécdotas cotidianas y, en general, de un eslabón de vinculación de pensamiento de los grupos. El discurso oral compendia un hecho que revela relaciones sociales y delinea identidades y culturas propias.

La oralidad más allá de su función de vinculación humana identifica una manera de entender un mundo particular. Es así como la palabra hablada concurre como intermedio de preservación de los distintos acervos culturales mediante la transmisión de los conocimientos ancestrales. Al igual que otras formas de lenguaje, como el escrito o el gestual, la oralidad, para aludir a Paz (1972), constituye un sistema expresivo dotado de poder significativo y comunicativo, donde la palabra refiere a una cierta potencialidad de direcciones y sentidos que desde tiempos inmemoriales ha 
primado en el desarrollo de las distintas civilizaciones. De otra parte, para Montemayor (1996) la oralidad comprende el arte de la lengua como transmisión de conocimientos, la comunicación oral como forma de relación y el habla como la capacidad dialogante de socialización.

La oralidad de los pueblos ha representado su máximo patrimonio, pues a través de la tradición oral la palabra delata el contexto cultural del que es su producto, el legado de los pueblos que identifica costumbres, acontecimientos, interpretaciones de la realidad, saberes culturales que explican el mundo comunitario, informa desde rituales y conocimientos técnicos y tecnologías de historias que incluyen lo trascendente y lo cotidiano. Como lo expresa la Unesco (2003) la oralidad de los pueblos incluye usos, expresiones, conocimientos, técnicas, junto con instrumentos objetos, artefactos y espacios culturales. Tales herencias culturales o legāre se soportan en la memoria, la cual archiva la experiencia en la cual, por ejemplo, los grupos minoritarios indígenas mantienen su supervivencia. (p. 3-6)

Es así como ante un legado ancestral viabilizado por la oralidad un grupo humano puede recuperar experiencias, evaluar procesos culturales con diferentes destinos y vincularlos a soluciones de problemáticas presentes. Es el caso de la contemporaneidad en los cuales, algunos de los muchos países como Colombia o Venezuela, cobra relevancia la cultura indígena que ha sido prevista en los cánones legales y en igualdad de derechos protegidos por la palabra a través del palabrero, al igual que el Tribunal de Aguas de Valencia-España- el cual lleva once siglos reuniéndose todos los jueves en la Puerta de los Apóstoles de la Catedral de Valencia, resolviendo los conflictos que se originan entre acequieros por la distribución del agua del río Turia, ejemplo claro, latente y vigente del sistema oral. Sin embargo, señala Civallero (2006), en las sociedades con texto escrito se localizan nichos en los que esta forma de comunicación no es la regla sino la excepción, es así que se conserva lo oral.

En la difusión del conocimiento el apoyo de la imprenta proporciona una mayor eficiencia, suministrando la posibilidad de saber de buena tinta los cambios y desarrollos en todas las sociedades, contribuyendo ampliamente en la producción de trabajos antropológicos como parte de los estudios culturales. Ahora bien para difundir la experiencia de la oralidad, solo se requiere un nivel básico de la lengua propia para ingresar al universo de lo hablado, contado y compartido en público o en familia, acogido en las voces de sus protagonistas. Con su evolución mucha sabiduría se mueve a través de los circuitos orales. Allí existen y reinan los ancianos memoriosos, los poetas, los relatores, los cuentacuentos o los rapsodas. Aunque también reside en las celdas monacales de los escribas, los claustros expertos y las bibliotecas de siempre. No en vano algún anónimo refería a ese sitial del habla escrita y de las memorias humanas, como: "Un tercer mundo en el que ante su falta los hombres pasarían sobre las cerillas muriendo de frío" (Civallero, 2006, pp. 26-27).

\section{La oralidad en las culturas primeras}

Los aedos personificaron profesionales del oficio de cantar acompañados con un instrumento de cuerda similar al laúd o a una lira pequeña. Abundaban los aedos ciegos como Demódoco, el cantor que amenizaba las veladas en la corte de Alcinoo, rey de los feacios de La Odisea, quien cantó ante Ulises episodios de la guerra de Troya (Homero, Canto III).

Luego, los poemas dejaron de ser cantados para ser recitados, por los llamados rapsodas, o zurcidores de cantos que podían empalmar unos cantos con otros o, diferentes partes de un 
mismo canto pemitiéndose alterar el orden de su relato recitando al ritmo de un bastón para su verso en ese momento de la antigua Grecia. En África, que comparte cantidad de pueblos ágrafos, el Djele-Griot era y es uno de los personajes más representativos y respetados de la tribu, con una tradición de al menos 1600 años. Actuaban estos, además, como consejeros de los líderes tribales.

Bien adelante en el tiempo, ¡todo está en la palabra! diría Neruda en 1974: "Tienen sombra, transparencia, eso, plumas, pelos, tienen de todo lo que se les fue agregando de tanto rodar por el río, de tanto transmigrar de patria, de tanto ser raíces... Son antiquísimas y recientísimas" (Neruda, 2011, p. 58). Pero al comienzo del calendario gregoriano se dijo, en el libro católico de la Biblia, refiere en los escritos de Mateo que: "No solo de pan vive el hombre, sino de toda palabra que sale de la boca de Dios" (Nuevo testamento, - Reina Valera, 1960). Sumado a ello, se reconoce también en libros sagrados de creación como el Popol Vuh, el Chilam Balam, el Rabinal Achi, declaradas obras maestras de la tradición oral, o el Memorial de Sololá, de pueblos indígenas en Yucatán y en Guatemala.

Todos son expresiones de un pensamiento mítico ancestral que identifica concepciones fundamentales de las culturas arcaicas y surge como respuesta sobre el mundo y su misma existencia. Como lo explica Eliade, este pensamiento se percibe: "[...]como una historia verdadera, y lo que es más, una historia de inapreciable valor, porque es sagrada, ejemplar y significativa" (2011, p. 5). Reconoce entonces que las mitologías primitivas que se han conocido en estadio oral, se han transformado y enriquecido o por otras culturas superiores o por hombres dotados para ello.

Aún hoy, en las comunidades campesinas la oralidad se privilegia a la escritura, los relatos perpetúan cosmovisiones de siglos que explican el origen de cada elemento y el significado de cada símbolo mágico, explicando curas para todo tipo de males del cuerpo y del alma, transmitiendo cantares, dichos o proverbios que reflejan el espíritu del pueblo, su sabiduría, su idiosincrasia y su modo de actuar en el mundo y de comprenderlo. En las sociedades urbanas la trasmisión oral mantiene vivos recuerdos familiares y grupales en historias de migración hacia dentro y fuera, puntos de vista particulares sobre grandes acontecimientos nacionales, tradiciones, juegos, artesanías y cuentos que solo se transmiten oralmente y no suelen coincidir con los oficiales. Manifestaciones culturales teatrales, las canciones, la música, las telenovelas llevan consigo signos de oralidad. También sucede con los grupos desplazados del campo a las ciudades, con dolo y necesidad que traducen identidad e historia significativas.

En el pasado, el choque de culturas que sucedió al proceso de colonización generó la pérdida de historias, de narraciones, se silenciaron tradiciones y de las lenguas irrespetadas solo algunas lograron preservarse. Con cada lengua extinta un caudal de información se va con ella, pues el lenguaje representa un medio expedito para simbolizar la realidad. Con su extinción se liquida un código de comunicación y una percepción de la existencia.

Actualmente, según Lee (2010), el multilingüismo en América Latina se mapea a través de los países. En Colombia se hablan unas 70 lenguas, en Perú unas 60, en México alrededor de 50, en Bolivia 30, en Guatemala 20, en Chile 10, aproximadamente. No todas conservan su 
fortaleza y algunas de ellas podrían estar a punto de extinción. El náhuatl que hablaban los aztecas antes de la llegada de los españoles funcionaba como lengua franca o común dentro de su imperio. Hoy lo hablan unos 2 millones de habitantes en México, Guatemala y El Salvador. El quiché es la lengua maya más conocida y la hablan en el sur de México, en Guatemala y en Honduras más de medio millón de personas. El quechua, idioma oficial del imperio Inca lo hablan aproximadamente 11 millones de personas. El aimara, también en Bolivia y Perú, tiene algo menos hablantes que el quechua. El guaraní se habla sobre todo en Paraguay y el mapuche es el idioma indígena más hablado de Chile, pues se calcula que actualmente lo usan cerca de medio millón de personas. Otras lenguas, en cambio, tienen un reducido número de hablantes, pero su variada representación de culturas orales en Latinoamérica evidencia una oralidad que es legado ancestral perviviente en estas comunidades latinoamericanas.

\section{Oralidad y memorias de grupo}

El sustentar la memoria colectiva en la tradición oral emplaza la preservación del lenguaje del grupo. Hay algunos autores que han incursionado en la comprensión de dichas memorias grupales. Uno de ellos en La memoria colectiva, observa que como asiento de la oralidad: "Contribuye a evocar y mantener recuerdos impersonales, en la medida en que estos interesen al grupo" (Halbwachs, 2004, p. 52). El autor en su disertación alega que la memoria colectiva evoluciona distinto que las individuales, pero las envuelve. Estas últimas: "Cambian de rostro en cuanto vuelven a colocarse en un conjunto que ya no es una conciencia personal" (p. 54); permite preservar la herencia social y manifiesta una dinámica de representaciones entre memoria personal y memoria social. Halbwachs distingue entre memoria colectiva e historia, diferenciándolas en el hecho de ser vividas o ser aprendidas; la historia sofoca la tradición, mientras que un recuerdo sigue vivo mientras haya testigos que lo conserven. Lo explica el autor: "Como cuadro de acontecimientos y las memorias colectivas como foco de tradiciones" (p. 84).

En otro sentido, memoria social y patrimonio se hacen coincidentes al ser ambas una construcción social que permite reelaborar la continuidad entre pasado y presente e identifica significados y sentidos que son compartidos en los grupos sociales como patrimonio cultural.

Tales elementos culturales, para Bonfil (1991) dinamizan las acciones sociales en su función de "[...] mantener la vida cotidiana, satisfacer necesidades, definir y solventar problemas, formular y tratar de cumplir aspiraciones [...]" (p. 171). Según la naturaleza y propósito de cada acción cultural pueden ser materiales, formas de organización, de conocimiento, simbólicas, emotivas o subjetivas; estas últimas incluyen las representaciones colectivas y las creencias. Es lo que la Unesco (2003) ha denominado el patrimonio cultural inmaterial este se manifiesta en las tradiciones y expresiones orales de un grupo; entendiéndose tradición oral como "[...] el conjunto de todos los tipos de testimonios sobre el pasado que son transmitidos verbalmente por un pueblo" (p. 8). El patrimonio se recrea a través de sus prácticas y formas de expresión, la tradición evoca la idea de transmisión y su labor de legar.

Al respecto, en Memoria cultural y comunicativa, Assmann (2008), un estudioso de las culturas egipcias precristianas, expone estos conceptos retomando el estudio sobre la memoria colectiva ya señalada por Halbwachs. La expresión memoria colectiva plantea la conexión entre tiempo, identidad y memoria, lo que es a su vez una memoria cultural. Esta última ha de ser: "Exteriorizada, objetada y almacenada en formas simbólicas que, a diferencia de los sonidos de palabras o de 
la visión de gestos, son estables y trascendentes a la situación" (p.118), de allí su condición de ser transferibles. El papel de los símbolos externos resulta significativo para el recuerdo y así se construyen [...]" "monumentos, museos, bibliotecas, archivos y otras instituciones mnemónicas" (p. 119). Este conocimiento del pasado o uso de la memoria se relaciona con un concepto de identidad. La memoria cultural es local y específica a un grupo y sus valores respondiendo a un orden ceremonial con grados de complejidad, objetivación y abstracción como los mitos orales o los ritos cívicos y placas conmemorativas que identifican lugares o personajes, entre otros símbolos.

\section{Oralidad y la cultura de la imprenta}

La historia identifica en la baja Edad Media la realización de copias manuscritas, hechas fundamentalmente por monjes escribanos. En ese momento la xilografía era utilizada en China, Japón o Egipto para reproducir dibujos. Incluso antes de estos puntos históricos había otras formas de reproducción, pero se le ha asignado a Gutenberg el papel inicial de la impresión tipográfica. Hijo de orfebre, alemán, su interés fue editar la Biblia de 42 líneas y en dos columnas alrededor del año 1440. Se trataba de las Escrituras de San Jerónimo en versión latina, editada en 120 ejemplares y 20 en pergamino. Fundida en metal cada una de las letras del alfabeto ideó un sistema para ponerlas de manera continua y sujetarlas, agilizando la composición de las páginas. Tras un largo salto hacia este lado del mar, la aparición de la prensa en México llega con los jesuitas hacia 1539 (Medina, 1958).

En Colombia las primeras publicaciones de la Compañía de Jesús están fechadas en 1738. La Imprenta Real sería fundada en 1777 y la Gazeta de Santa Fe hace el primer tiraje de la prensa oficial. Luego, la existencia de la Imprenta Nacional está vinculada a la gestión de gobernantes y dirigentes que se disponían a: "Garantizar la fidelidad jurídica y administrativa, mediante la reproducción y la divulgación de las normas oficiales, para la conservación de la memoria del Estado de generación en generación" (Medina, 1958, p. 1). La llegada de la primera imprenta en Colombia concuerda con la independencia política del siglo XIX, para Loaiza (2014), entre muchos autores, en esas luchas intervinieron personajes cercanos a ese avance técnico que entendieron el poder de la lectura y escritura. Estos: "Tenían un reto apremiante, construir una estabilidad en la comunicación política, fabricar la ilusión de noticias ciertas, sistemáticas y, por supuesto oficiales [...]" (p. 45). La cultura impresa fue un novedoso medio para la circulación de la oralidad en nuevas formas y usos de impacto social.

En el mundo la difusión de talleres, la rapidez del proceso en contraste con los escribas. La producción en la era de la imprenta manual, sobrecarga de trabajo a bibliotecarios y estudiosos del siglo XVII y lo mismo sucedería al llegar la imprenta de hierro y vapor. Este fenómeno acompasa el progreso de la Reforma protestante, el Renacimiento y la ciencia moderna. En paralelo la oratoria pública, de mucho antes en la historia con Quintiliano en el siglo I, y la alocución, eran valoradas y enseñadas en las escuelas de derecho quince siglos después para formación de abogados expertos en alegatos.

En su texto La Revolución de la imprenta en la Edad Moderna Europea, Eisenstein (1994) realiza observaciones a las obras de MacLuhan y Vansina en tanto considera que ambos, como algunos 
historiadores lo hacen, parecen centrar en la invención particular de Gutenberg el único factor de cambio europeo, en una interpretación que resulta causal.

Le parece poco acertado que se perciba el cambio de una cultura oral a una cultura impresa, en una amnesia histórica, pues si bien la imprenta modificó la comunicación escrita dentro de la Republica del conocimiento, lo que sí alteró fueron los métodos de recopilación de datos, los sistemas de su almacenamiento y recuperación y las redes de comunicación usadas por las comunidades letradas de toda Europa.

Para recordar el abismo entre las culturas oral y letrada Eisenstein considera impreciso adjudicar a la imprenta el hábito de la lectura del silencio que señala McLuhan, pues esto se hacía en la época de los amanuenses. La recurrencia a los instructores callados no generó que se disminuyera el recurso a la palabra hablada en todos los casos. La industria editorial no eliminó las lecciones de clase, ni la prédica en los púlpitos o las disertaciones de los rectores de sus palestras, todas disertaciones y sermones que impresas robustecían el carisma personal de sus emisores. A pesar de la revolución impresa las prácticas de transmisión oral y los circuitos de recepción no desaparecieron.

\section{Reconocimiento contemporáneo de la oralidad tradicional}

Autores como Parry (1971); Lord (1960); McLuhan (1962); Havelock (1963); Godoy (1977), y posturas divergentes como Derridá (1967); Levi-Strauss (1975) o Finnegan (1987), según Ong (1987), reconocen que los poemas homéricos, producción hito para el mundo occidental, pertenecen a la historia oral y estudian cómo ha sido su proceso de conservación y transmisión. En ese sentido escribe Petrie (1995) que la conquista de la Eólide es la simiente histórica del corpus de la poesía épica: "Que luego brotará en Jonia y es universalmente conocido bajo el nombre de Homero" (p. 12). Ciertamente la épica fue el género literario más influyente en esos momentos con su manifiesta expresión narrada de valores espirituales y artísticos, pues las pequeñas distinciones del lenguaje, entre los poemas homéricos, son calificadas por algunos estudiosos como la razón para creer que hasta entonces habían sido transmitidas oralmente.

Al respecto, Wolf en su obra Prolegómenos de Homero de 1795 intentó demostrar que dichos escritos fueron fragmentos épicos compuestos por distintos aedos y de épocas distintas, con lo cual no asumió la hipótesis de que no pertenecían a Homero (Wolf, 1985). Parry (1971) defiende el carácter oral de la obra homérica y en su tesis El epíteto tradicional en Homero reconstruyó los métodos orales de composición de los poemas homéricos, para lo cual realizó un análisis del verso explicando que no era el significado la cantidad de epítetos utilizados, sino que su autor recurrió a ellas por las necesidades métricas del verso hexámetro.

Las ideas de Parry fueron compartidas y continuadas por Lord (2000), profesor de literatura eslava, quien estudió la experiencia oral en grupos yugoslavos y bosnios vinculados a la épica homérica encontrando estrecha coincidencia. De su extensa disertación llega a que la adición y el uso de repeticiones son propios de la tradición oral, representando un arte continuo que viene al presente y sigue más allá mientras la tradición viva.

Havelock (1994) es un autor también preocupado por las condiciones de producción y transmisión de, principalmente, la tradición oral. Con referencia a diversos textos de países diferentes en los que el estudio del tema sobre la tradición oral y el tránsito a la escritura lleva a sus repercusiones sobre la manera de concebir la naturaleza y las relaciones sociales, en la vida religiosa y en la 
acción poética. Entre estas obras, El pensamiento salvaje de Lévi-Strauss; "The consequences of Literacy”, artículo de Goody y Watt, La Galaxia Gutenberg de McLuhan; Animal Species and Evolutio de Mayr, y su propia obra Prefacio a Platón, de 1994 (Havelock, 1996, p. 48-49). Con esto demostró el interés contemporáneo por la experiencia oral, su vigencia y transición desde épocas anteriores.

La oralidad y la escritura son complementarias, resultando en distintas formas del lenguaje. Los pueblos orales consideraban la palabra como otorgadora de poder pues cada individuo sabía solo lo que era capaz de recordar. La enunciación oral que se origina en el interior de los organismos vivos es dinámica y las palabras entrañan un potencial mágico. Havelock indica: "La palabra hablada real no puede ser rotulada como en la escritura" (p. 40), esto muestra el poder de la representación que permite la palabra en su sentido sonoro y como signo, pues las palabras son sonido, tal vez se les llame a la memoria, se les evoque pero no hay lugar para verlas, no tienen foco ni huella ni siquiera una trayectoria.

De esta manera, las palabras son acontecimiento, hecho, no hay texto externo al pensador que facilite recordar una y otra vez. Es esencial un interlocutor, pues el pensamiento sostenido está vinculado con la comunicación. Retener y recobrar el pensamiento sigue reglas mnemotécnicas, pautas equilibradas e intensamente rítmicas, marcos temáticos comunes, proverbios conocidos por todos de manera que vengan a la mente con facilidad. Por ello quizá los refranes y proverbios representan fórmulas constantes en las culturas orales. La ley misma está impregnada de estos recursos formulaicos, ellos mismos constituyen las normas escritas.

El pensamiento y la expresión en una cultura oral tienden a tener alguna caracterización según Ong (1982), quien establece una interesante tipificación en ese sentido. Ser (a) acumulativas antes que subordinadas, pues el discurso oral despliega una gramática menos elaborada y fija que la escrita. Son (b) acumulativas antes que analíticas, en cuanto una dependencia de las fórmulas para practicar la memoria. La tradición popular oral prefiere en el discurso formal una carga de epítetos, en contraste con el pensamiento que analiza y totaliza, representando una creación artificial, estructurada por la tecnología de la escritura. Pueden ser, (c) refundantes o copiosos, pues en el discurso oral el enunciado desaparece en cuanto es articulado, de manera que la redundancia, la repetición de lo apenas dicho, mantiene eficazmente tanto al hablante como al oyente en la misma sintonía, estimulando la fluidez, el exceso, la verbosidad, intensas en la cultura occidental mientras mantuvo huellas de la tradición oral. Suelen ser (d) conservadoras y tradicionalistas, pues la originalidad narrativa consiste en lograr una reciprocidad particular con un público en un momento, se acude a viejas fórmulas y temas con las nuevas situaciones políticas a menudo complicadas; estos son reorganizados antes que reemplazados por material nuevo. Los nuevos universos conceptuales de las prácticas religiosas y con ellas las cosmologías y las creencias llegan a existir en una economía intelectual esencialmente formulaica y temática, ajustada a las tradiciones de los antepasados.

Continúa Ong afirmando que (e) cerca del mundo humano vital, en ausencia de categorías analíticas complejas de la escritura, la cultura oral no posee nada que corresponda a manuales de operación para los oficios que son adquiridos a través de la observación y la práctica, con una mínima explicación verbal. Hay en lo oral (f) matices agonísticos, incrustados en el mundo vital humano, pues la oralidad sitúa el conocimiento dentro de un contexto de lucha, alabanzas, 
intenciones polarizadas del bien y del mal, la virtud y el vicio, los villanos y los héroes. Igualmente, las expresiones orales son (g) empáticas y participantes antes que objetivamente apartadas, pues en una cultura oral aprender o saber significa lograr una identificación comunitaria, empática y estrecha con lo sabido. También, son (h) homeostáticas, las sociedades orales pues para su equilibrio viven desprendiéndose de los recuerdos que ya no tienen pertinencia actual. Las culturas orales no cuentan con diccionarios y tienen pocas discrepancias semánticas.

Las palabras adquieren su significado de un ambiente que incluye gestos, modulaciones vocales, expresión facial y todo el marco humano y existencial dentro del cual se produce siempre la palabra real y hablada. Finalmente, son (i) situacionales antes que abstractas, pues las culturas orales tienden a utilizar los conceptos en marcos de referencia situacionales y operacionales que se mantienen cerca del mundo humano vital. Resulta claro entonces que Ong enmarca su análisis en la consideración del influjo de las tecnologías comunicacionales como la oralidad, la escritura, imprenta, medios eléctricos y electrónicos en la psique y la cultura de las comunidades: "En la conformación de visiones de mundo, sistema de valores, nociones de tiempo".

Ahora bien, pasaremos a estudiar dos grandes hitos históricos de la humanidad en los cuales se refleja el sistema oral de manera viva además de vigente tras haber soportado el paso de los siglos, de la contemporaneidad y sus cambios para convertirse en un testigo vigente de los sistemas jurídicos que ellas reflejan y contienen, los cuales son el sistema oral indígena Wayuú y el Tribunal de las Aguas de Valencia.

\section{El lugar de la palabra en la Ley de origen}

La ley que ha regido los pueblos originarios antes del establecimiento de los Estados nacionales modernos es nombrada como Ley de origen, es decir, ley natural o Derecho mayor -Derecho propio, bien descritas en el texto Somos hijos del Sol y de la Tierra, luego del encuentro en Quito en 2007 de líderes y autoridades indígenas. Allí Lorenzo Muelas, Gobernador del pueblo colombiano guambiano, del centro-oriente del departamento del Cauca, refiere al Derecho Mayor inscrito en el hecho:

A nosotros nos parió la tierra, un gran caudal, una avalancha hizo nacer a nuestro pueblo...hace 10, 20 y 30 mil años nos desarrollamos, y nosotros somos herederos de esos antepasados, y somos hijos de ellos y somos parte de ese derecho. (Bonilla, 2007, p.10).

Es así como en Colombia, diversas culturas ancestrales se rigen por la Ley de origen. Los guambianos, muy firmes, expresan que el derecho mayor está por encima de escrituras, leyes, armas, poder: "Por Derecho Mayor; por derecho de ser primeros, por derecho de ser auténticos americanos. En esta gran verdad nace todito nuestro derecho, todita nuestra fuerza. Por eso debemos recordarla, transmitirla y defenderla" (p. 12).

De otra parte, un juez del pueblo Pijao expresa el significado de la lengua y le adjudica el conocimiento: "De la montaña, de la nieve, del mar y de las estrellas. Esa lengua habla y expresa todo eso..." (p. 48). Es el resumen de la identidad que percibe y que les permite que la justicia este unida al territorio y a la espiritualidad, se consulta con los espíritus el castigo adecuado cuando suceden los desequilibrios. 
Para el pueblo Arauco-Tayrona, de la Sierra Nevada de Santa Marta, la justicia está vinculada al territorio. Este pueblo a través de su Ley de origen considera que la identidad la cultura y la justicia: "[...] responde a la aplicación de la espiritualidad, nosotros tenemos un conocimiento ligado al cosmos, al territorio, al pozo sagrado, a los árboles, a las piedras. Todo está integrado", "cuando se produce desequilibrio se castiga a la persona...para que todos se curen y con ellos la naturaleza" (Bonilla, 2007 p. 51).

Para el pueblo Nasa, caucano pero extendido a otras regiones del país, la Ley de origen es la palabra cargada de espiritualidad, de historia de vida de un pueblo, de una nación indígena: "Nos enseña cómo surgió nuestro mundo, qué debe hacer y cómo debe comportarse y cuál será el final de todo, que se materializa en lo que se llama Plan de Vida" (párr. 15). Por ello, comprender este inicio es comprender todo lo venidero, dando sentido -o más bien otros sentidos- a las cosas, a la vida.

El pueblo Wayuú, traducido como nosotros las personas, tienen asentamientos dispersos en la alta, media y baja Guajira colombiana y comparte tierras con Venezuela, representando el 11\% de la población del Estado Zulia y cerca del 19,42\% del departamento de La Guajira (Dane, 2005). La mayoría vive en los llamados resguardos indígenas, con límites establecidos por la ley, ocupado por uno o más grupos étnicos: "Con organización social propia y con títulos de propiedad colectiva, inembargable e intransferible" (Dane, 2005). Su organización como grupo étnico los califica como beneficiarios del principio multicultural y pluriétnico que ordena la Constitución colombiana vigente.

Según el escritor Wayuu, Paz Ipuana (1981): “Lo que siempre es lo que es. Tal es la ley, el ordenamiento" (p. 48). Para alegar ética en la funcionalidad del grupo. La esencia espiritual la deben preservar y manifestar con comportamientos armónicos en su vida cotidiana y familiar; cuando por el contrario surge un conflicto acuden al pütchipü'ü, o palabrero, como mediador para extraer lo malo y obtener enseñanzas del acto cometido, quien lleva la palabra y peticiones de la parte ofendida, explica al grupo reunido la situación de trasgresión de la norma social, se dirige al infractor y espera sus argumentaciones. El dictamen parte de la solicitud de la familia agredida cuando requiere compensación del agravio recibido. El palabrero básicamente es un intermediario, pero puede llegar, depende de su prestigio, hasta realizar propuestas concretas para que el conflicto finalice. Existen dos clases de ofensas, las que violan las costumbres y las que violan las obligaciones. Las mejores experiencias en la solución de conflictos dan carácter para ejercer la función de palabrero, aunque también ser palabrero se aprende en compañía de un familiar que ejerza dicha función.

\section{El Tribunal de Las Aguas de Valencia}

En Valencia, España se puede encontrar, dice Carpi (2008): “El único ejemplo en Europa, que yo sepa, de un antiquísimo modelo de proceso completamente oral: el que desarrolla aún hoy cada jueves delante de la Puerta de los Apóstoles de la Catedral ante el Tribunal de las Aguas". Se aproxima el análisis a la función jurisdiccional del tribunal de resolver los conflictos generados por el uso indebido del agua para decidir si condena o absuelve a quien cometiera alguna infracción de las mismas. El proceso se rige por normas iniciadas en tradición oral e incorporadas más tarde como ordenanzas. 
El proceso se realiza de la siguiente manera:

"La persona denunciada es citada por el Guarda de la acequia para el jueves siguiente. Hasta dos veces más es citado y, si no acude tampoco a la tercera citación, tras admitirse la denuncia, se le juzga en rebeldía pudiendo ser condenado. Nunca ha sido necesario acudir a la fuerza pública para hacerle comparecer. Se sientan los sindicas en los sillones asignados a cada una de sus respectivas acequias. Asiste el Alguacil del Tribunal, antaño guarda mayor o verdadero "atandador", encargado de dar el agua y levantar las compuertas o paradas, portador como insignia de un impropio arpón de latón dorado, de dos púas, una de ellas encorvada, que el instrumento con que separaban y recogían las tablas de las ranuras de los partidores. El Alguacil solicita del Presidente la venia para iniciar las citaciones y llama públicamente: "IDenunciats de la Séquia de Quart!", y acuden los denunciados, si los hay, acompañados por el Guarda de la Acequia. Las citaciones se van haciendo por el orden en que las acequias toman el agua del río, iniciándose por la de Quart, que es la primera, y terminando por la Robella, que es la última”. (Tribunal de las Aguas, 2017).

Mucho se ha escrito sobre esta institución de la comunidad de Valencia, provincia del este de España, un territorio industrializado, con un potente sector turístico y una intensa actividad agrícola. Dos textos destacados permiten percibir la trayectoria e importancia del dicho Tribunal de las Aguas, cuya legitimidad constitucional se basa en la costumbre "y la costumbre se sostiene sobre la reiteración de actos, acompañada de la opinio iuris seu necessitatis" (Fairén, 1988). Este primer texto, El Tribunal de las aguas de Valencia y su proceso: oralidad, concentración, rapidez, economía y el segundo, resultado del Coloquio coordinado por Mascarell (2008). El Tribunal está conformado por el presidente, el vicepresidente, el aguacil, guardas, síndico y secretaría.

Según Fairén (1988) el Tribunal de las Aguas o Tribunal de los Acequieros de la Vega de Valencia, es de vieja data y de amplia actividad desde la Edad Media cuando se realizaban consultas y no juicios, entre aquellos que conocían la costumbre de la Huerta. Parte de la autoridad del cequier se sometía al examen y consideración de los regantes de la Huerta; igualmente, los asuntos no judiciales del riego eran sometidos a sus auctoritas. Una señal posterior de su existencia se encuentra con los Privilegios y Fueros concedidos por Jaime I y Jaime II de Aragón, que aunque no crearon el tribunal dichos privilegios permiten reconocer su existencia. Junto con las ordenanzas propias de cada acequia se fue conformando en la época foral su régimen jurídico. Derecho foral o derecho especial en España lo califica como el conjunto de ordenamientos jurídicos de derecho privado que se administran en algunas comunidades autónomas, coexistiendo con el Código Civil Nacional.

Mediante el derecho otorgado se donaba a los pobladores de Valencia las acequias del río Turia para que pudieran regar y fertilizar los campos. Una junta administradora y el síndico-presidente eran elegidos entre miembros de la comunidad y con la condición de hombres honrados y ser labradores directos de las tierras. Los acequieros síndicos de las 8 acequias: las de Tormos, Rascaña y Mestalla, las de Cuart, Benacher y Faitanar, Mislata, Favara y Na Rovella vigilaban que se distribuyera el agua por las 138 filas en que se dispensa el agua y trabajaban en conjunto con 
el Guardia de la acequia, el cual conducía la distribución equitativa del agua y evidenciaba las infracciones cometidas para ser juzgadas en el Tribunal de las Aguas.

Los documentos legales del tribunal están constituidos por ordenanzas que contienen turnos de riego, obligación de limpieza de canales y acequias, pagos para gastos generales. Las sentencias que se dictan son acatadas por lo cual no se registra que acudan a la jurisdicción ordinaria para su cumplimiento. Según la Ley Orgánica del Poder Judicial de 1985, el Tribunal tiene: "El carácter de Tribunal consuetudinario y tradicional". Para Fairén: "Como fuentes del proceso se halla la costumbre "de extraordinaria limpieza y frescura" (p. 5). Según el aparte De los Organismos de cuenca, en la configuración y funciones establece que es un organismo adscrito al Ministerio de Obras Públicas y Urbanismo, a efectos administrativos, pero con plena autonomía funcional; así está escrito en el artículo 20 de la Ley de Aguas, 1985.

Las categorías definitorias del tribunal, señaladas por Fairén, son oralidad, concentración, rapidez, economía (1988):

a. La Oralidad es la condición subyacente a todo juicio que contempla la denuncia-la sentencia-la indagatoria. El presidente y los síndicos interrogan verbalmente a las partes.

b. La Concentración significa que los síndicos poseen instrucción procesal lo que les permite proceder judicialmente ante el caso, en el cual están presentes el acusado, el labrador perjudicado los cuales pueden aportar pruebas y testigos.

c. La Rapidez envía a que las infracciones cometidas se procesan semanalmente, todos los jueves, en 21 días como máximo; esto último se aplica en caso de incomparecencia de los denunciados.

d. La Economía significa que siendo el juzgar parte de las obligaciones de los síndicos de las acequias la actividad procesal no ocasiona gastos. El único importe de gastos lo abona el denunciado para sufragar el desplazamiento de los Guardas o Alguacil del Tribunal.

En el texto coordinado por Mascarell (2008), estudiosos valencianos acogen el debate alrededor del pasado presente y futuro del Tribunal de Aguas, pero se enuncian algunos elementos que han puesto en dificultades su existencia. La primera crisis la asocia al artículo 117.5 de la Constitución española de 1978 que estableció el principio de unidad jurisdiccional como base de organización y funcionamiento de los tribunales. Como aval a favor el artículo 19.2, de la Ley Orgánica del Poder Judicial, LOPJ, ordena que en la administración de justicia puedan participar... en los Tribunales consuetudinarios y tradicionales y en los demás casos previstos en esta Ley. Así mismo señala: "El carácter de Tribunal consuetudinario y tradicional al Tribunal de las Aguas de la Vega Valenciana".

Entre los riesgos se enuncian: “La progresiva desaparición del aprovechamiento económico del territorio sobre el que el Tribunal extiende su jurisdicción y que justifica la materia respecto de la cual esa jurisdicción es ejercida". La propuesta acerca de tal amenaza es la disposición del tribunal, es que su exitosa experiencia aporte a la discusión científica y sirva de asesoría y apoyo en la celeridad de los procesos de aplicación de justicia. 


\section{Conclusiones}

La oralidad sigue vigente en los ordenamientos legales, no solo en su reconocimiento a culturas minoritarias, sino en cambios introducidos a las prácticas procesales. Lo que puede reconocerse es su validez como práctica social y construcción humana. La oralidad, entendida como el intercambio verbal de ideas, es y ha sido una herramienta esencial en la comunicación y trasciende a la tarea jurisdiccional, como instrumento para facilitar el debido respeto a los derechos y garantías de los ciudadanos en un Estado de Derecho moderno. Como se ha expresado en recientes cumbres expertas: "Al permitir que la actuación del juzgador se acomode a criterios de inmediación y contradicción realmente efectivos" (p.2). El juicio público, solo posible en el ámbito de la oralidad, permite a una sociedad ejercer legítimas facultades de conocimiento y control: "Obviando una parte importante de los reparos que un sistema procesal escrito pudiera suscitar" (CJl, 2008, p. 2).

Cabe recordar que la oralidad en Iberoamérica, como lo ha expresado la Cumbre Judicial Iberoamericana (2008) ha sido practicada en lo procesal en Portugal desde el XV, en España, República Dominicana y Cuba desde el XIX. A través de la primera mitad del siglo XX instaurada en Colombia, El Salvador, México, Panamá y Puerto Rico. Luego de 1950 y hasta el año 2000, en Argentina, Bolivia, Costa Rica, Honduras, Nicaragua, Perú, Uruguay, Venezuela, Andorra (en la frontera este de España), Guatemala y Paraguay. A partir del 2000 se inició en Chile y Ecuador. La oralidad sigue viva en el mundo tecnológico de hoy, aunque la escritura es, acompañando a Halbwachs, "la institución mnemónica por excelencia".

Actualmente el sistema oral es frecuentemente utilizado para la resolución de conflictos en el sistema Wayuú a través del palabrero siendo este (sistema) la única forma para encontrar solución a los problemas que aquejan a los clanes, método utilizado de igual manera a miles de kilómetros en Valencia- España- con una gran diferencia, aquí dirigido por un tribunal milenario, pero ambos sustentados en la oralidad, la inmediatez y la compensación, lo cual demuestra la vigencia y efectividad de la oralidad.

\section{Referencias bibliográficas}

Assmann, J. (2008) Memória comunicativa e memória cultural. Tradução: Méri Frotscher

Bonfil B. G. (1991). Pensar nuestra cultura. México: Alianza editorial.

Bonilla. O (2007). Somos hijos del sol y de la tierra. Derecho mayor de los pueblos indígenas de la cuenca amazónica. En: http://www.oilwatchsudamerica.org/docs/el_derecho_mayor.pdf

Carpi, F. (2008). Oralidad y escritura en un proceso civil eficiente. Universitat de Valencia. Recuperado de ttps://www.uv.es/coloquio/coloquio/program.htm

Civallero, E. (2006). Voces en el silencio. Editorial Biblos, Año 7, 25-26, Jul-Dic. Argentina. Universidad Nacional de Córdoba. Recuperado de https://www.academia.edu/10431161/Voces_en_el_silencio

CJI (2008) La oralidad procesal en Iberoamérica. XIV Cumbre Judicial Iberoamericana, Brasilia, 4 a 6 de marzo 
Eisenstein, E. (1994). La revolución de la imprenta en la Edad Moderna europea. Recuperado de : https:// books.google.com.pa/books?id=RFOHOqiHv_AC\&pg=PA128\&lpg=PA128\&dq=entrevista+a+Elizabeth+Eisenstein\&source=bl\&ots=14EbsSLUXp\&sig=E9cWapKJYmfmk-GEKN18pXWzn7M\&hl=es\&sa=X\&ve$\mathrm{d}=0$ ahUKEwj-z8G_vs7XAhWkRN8KHa8uBiwQ6AEIYjAJ\#v=onepage \&q=entrevista\%20a\%20Elizabeth\%20 Eisenstein\& $\mathrm{f}=\mathrm{false}$

Eliade, M. (2011). Mito y Realidad. Barcelona: Editorial Labor.

Fairén G., V. (1988). El Tribunal de las aguas de Valencia y su proceso: oralidad, concentración, rapidez, economía. España: Caja de Ahorros y Monte de Piedad

Halbwachs, M. (2004). La memoria colectiva. Traducción de Inés Sancho-Arroyo. Editado por Prensas Universitarias de Zaragoza. Recuperado de http://cesycme.co/wp-content/uploads/2015/07/Memoria-Colectiva-Halbwachs.-.pdf.

Havelock, E. (1994) Prefacio a Platón. Madrid: Visor distribuciones, S. A. Recuperado de https://es.scribd. com/doc/132910340/HAVELOCK-Prefacio-a-Platon-pdf

Havelock, E.A. (1996). La musa aprende a escribir. Reflexiones sobre oralidad y escritura desde la Antigüedad hasta el presente. España: Paidós. Recuperado de https://monoskop.org/images/5/56/ Havelock_Eric_A_La_Musa_aprende_a_escribir.pdf

Loaiza, G. (2014). El poder letrado en Colombia. Ensayos sobre historia intelectual colombiana, siglos XIX y XX. Cali: Editorial Universidad del Valle. Recuperado de www.redalyc.org/pdf/3870/387049117032.pdf

Lord, A. (2000). El cantante de cuentos. $2^{\mathrm{a}}$ ed. Mitchell y Nagy, Eds. Recuperado de http://www.ling. upenn.edu/ rnoyer/courses/103/SingerOfTales.pdf

Mcluhan, M. (1962) La Galaxia Gutenberg. Génesis del "homo typographicus". Barcelona: Editorial: Planeta-Agostini.

Medina, J. (1958). Historia de la imprenta en los antiguos dominios españoles de América y Oceanía. Chile: Fondo histórico y bibliográfico José Toribio Medina. Recuperado de file://C:/Users/Exlim\%20Gil/ Downloads/MC0005167.pdf

Montemayor, C. (1996). El cuento indígena de tradición oral. México: Centro de Investigaciones y Estudios Superiores en Antropología Social-Instituto Oaxaqueño de las Culturas.

Neruda Pablo (2011). Confieso que he vivido. Memorias. Edición: Seix Barral. Recuperado de http://www. librosmaravillosos.com/confiesoquehevivido/pdf/Confieso\%20que\%20he\%20vivido\%20-\%20Pablo\%20 Neruda.pdf

Ong, W. (1982). Oralidad y escritura. Tecnologías de la palabra. Traducción de Angélica Scherp. México: Fondo de cultura económica. Recuperado de https://antroporecursos.files.wordpress.com/2009/03/ ong-w-j-1982-oralidad-y-escritura.pdf

Parry, A. (ed.), (1971).The Making of Homeric Verse. The Collected Papers of Milman Parry. Recuperado de file:///C:/Users/Exlim\%20Gil/Downloads/kupdf.com_parry-1971-the-making-of-homeric-verse.pdf

Paz Ipuana (1981). El Conejo y el Mapurite. Caracas: El Banco del libro. 
Paz, O. (1972). El Arco y la Lira. España: Fondo de cultura económica. Recuperado de http://www.ecfrasis. org/wp-content/uploads/2014/06/Octavio-Paz-El-arco-y-la-lira.pdf

Petrie A. (1995). Introducción al estudio de Grecia. México: Fondo de cultura económica. Recuperado de https://es.scribd.com/document/270629603/Petrie-A-Introduccion-Al-Estudio-de-Grecia

Reina Valera (1960). Santa Biblia, Editorial: Oliver Three.

Tribunal de las Aguas (2017). Recuperado de http://www.tribunaldelasaguas.org/es/el-tribunal/ funcionamiento

Unesco. (2003). ¿Qué es el patrimonio cultural inmaterial? Recuperado de https://ich.unesco.org/doc/ src/01851-ES.pdf.

Vansina, J. (1967). La tradición oral. Cap. 1 - La tradición oral y el método histórico. Recuperado de https://www.academia.edu/25394768/Jan_Vansina_1967___La_tradici\%C3\%B3n_oral_Cap._1_-_La_ tradici\%C3\%B3n_oral_y_el_m\%C3\%A9todo_hist\%C3\%B3rico_

Wolf, F. A. (1985). Prolegomena to Homer, Traducción y notas al inglés de Anthony Grafton y otros. Princenton Legacy Librery. Recuperado de https://books.google.com.pa/books?id=Ten_AwAAQBAJ\&p$g=P A 11 \& l p g=P A 11 \& d q=$ August+WOIf, + libros+on+line \&source=bl\&ots=0wsy-fvXt7 \&sig=8VKzGkThBw5KSVzhprwGQLRzzvg\&hl=es\&sa=X\&ved=0ahUKEwiOiueXrtDXAhXIOSYKHe_9ByYQ6AEIVDAI\#v=onepage\&q=August $\% 20$ WOIf\%2C\%20libros\%20on\%20line\&f=false. 